\title{
Land use dynamics in the context of variations in hydrological regimes in the upper Senegal River basin
}

\begin{abstract}
The objective of this study is to analisis the climatic vulnerability of water resources in the Senegal iver and Gambia basins. The study concerns the analysis of rainfall data, flow rates of Modis-Terra satellite images. Time series of study data are variable. The purpose of this study is to analysis climate vulnerability on water resources in the Senegal River and Gambia basins. It is based on the exploitation, on the one hand, of the chronicles of annual rainfall amounts and annual flows of the tributaries of the Bafing at the Bafing Makana station, from Senegal at the Bakel station, from Bakoye to Oulia and from Faleme to Kidira over the period 1955-2014 and, on the other hand, of Modis-Terra satellite images from 2007 and Modis-Terra from 2014. The calculation of rainfall and hydrometric indices and the application of statistical tests made it possible to analyze hydro-pluviometric variability in the Senegal River and Gambia basins. This variability is characterized by comparable fluctuations in precipitation and runoff. The break identified on the rainfall and hydrometric series from the late 1960 s onwards resulted in a rainfall deficit of $12 \%$ to $18 \%$ and a flow deficit of $66 \%$ after the break. The analysis of land use maps based on satellite imagery has made it possible to identify the dynamics of land use. This dynamic is characterized by the regression of natural plant formations in favor of anthropogenic ones. Fields and fallows experienced the greatest expansion with a rate of $7.8 \%$, bare soils $(8.8 \%)$. However, the forest and savannah experienced a decline of $(-10.35 \%)$ and water bodies $(-0.2 \%)$ following the 2007-2014 period. The degradation of the vegetation cover is undoubtedly one of the factors contributing to the persistence of the relatively high level of hydrometric deficit in the upper basin.
\end{abstract}

Keywords: cover degradation, hydrometry, drought, flow deficit, hydro, climatic variability
Volume 3 Issue 3 - 2019

\author{
Abdoulaye FATY,' Fernand Kouame, ${ }^{2}$ Awa \\ Niang FALL,' Alioune KANE' \\ 'Campus UCAD-IRD of Hann-Route of the Marist Fathers- BP \\ I 386 Dakar-Senegal, Senegal \\ ${ }^{2}$ University Center for Research and Application in Remote \\ Sensing of Abidjan, Senegal
}

Correspondence: Abdoulaye FATY, Campus UCAD-IRD of Hann-Route of the Marist Fathers- BP I386 Dakar-Senegal, Senegal, Email Abdoulaye.faty@ucad.edu.sn

Received: April 16, 2018 | Published: May 09, 2019

\section{Introduction}

Land use is a fundamental variable for regional planning as well as for the study and understanding of the environment. ${ }^{1}$ This theme has become unavoidable in most cartographic and monitoring inventories of environmental phenomena. ${ }^{2}$ Monitoring vegetation areas in the arid and humid areas of the Senegal River's high watershed has become a priority for policy makers and scientists alike since the advent of the 1970s drought, which followed a longer period of time. wet (19501969). The Senegal River watershed (Figure 1) is characterized by a predominance of subsistence farming, gathering and mining. These activities are in perpetual transformation because of the effects of climate change and the different adaptation policies. To understand the spatio-temporal dynamics of land use, it is necessary to regularly monitor vegetation cover from spatial imagery. But because of the characteristics of high spatial heterogeneity and local landscape variability, ${ }^{3}$ the detection of different categories of land-use systems remains difficult. For this reason, we relied on field data to perform the diachronic analysis of Landsat imagery for 2007 and 2014. The present study aims to analyze, over an interval of 08 years, the spatial dynamics of the different types of land occupations grouped into 5 categories, classified according to the LCCS model (Land Cover Classification System) of the classification of the occupation of the soil used by $\mathrm{FAO}^{4}$ wetlands, bodies of water, bare soil, areas of crops and fallows, savannah and dense forest. Although many uncertainties remain about the speed, amplitude and geographical distribution of climate change, its reality is now widely accepted in the scientific community and its consequences will have major impacts on our societies, on ecosystems, and natural resources. The Senegal River, with a catchment area of about $300,000 \mathrm{~km}^{2}$ and a length of $1,800 \mathrm{~km}$, is the second largest river in West Africa after Niger. The mother branch of the Senegal River, the Bafing, has its source in Mamou in the Fouta Djallon massif, from where also descends its main tributary of left bank: the Falémé. In this study, we looked at the mountainous area of the Senegal River watershed, called the Senegal River High Watershed. It is in this part of the basin that is made the junction of several tributaries including the Bafing, Bakoye and Falémé (Figure 2).

\section{Materials and method}

\section{The data used in this study are made up of}

Rainfall data: these are chronicles of annual rainfall amounts from four (04) stations located in the upper catchment area (Table 1). These chronicles cover the period from 1955 to 2014 and are obtained from the organization for the development of the Senegal River (OMVS).

Hydrometric data: these are chronicles of annual flows from the stations of Bafing, Bakel, Oualia, and Kidira (Table 1), located at the outlet of each sub-basin. Flow data cover the period 1955 to 2014 and are collected at OMVS.

Satellite images: For the analysis and mapping of land use dynamics, Modis-Terra mosaic images (250m), MODh16v07 and MODh17v07 
scenes from 2007 and 2014 were used. These two image scenes have been uploaded to modis.gsfc.nasa.gov/data/ in NCDF format.

\section{Data processing methods}

Several methods were used for the processes and analyzes of data and results.

Regionalization of rainfall data: The Thiessen polygon method was used for the regionalization of rainfall data. This method makes it possible to estimate weighted values by taking into consideration each rainfall station and to show an overall average of the series. ${ }^{5}$ It assigns to each rain gauge an area of influence whose area, expressed as a percentage (\%), represents the weighting factor of the local value. The average precipitation over the basin is obtained by this following formula (equ 1):

$$
P \text { moy }=\Sigma A i . P i / A
$$

With, Pmoy : average precipitation over the basin, A : total area of the basin, Pi : precipitation recorded at station i, Ai : area of the polygon associated with station

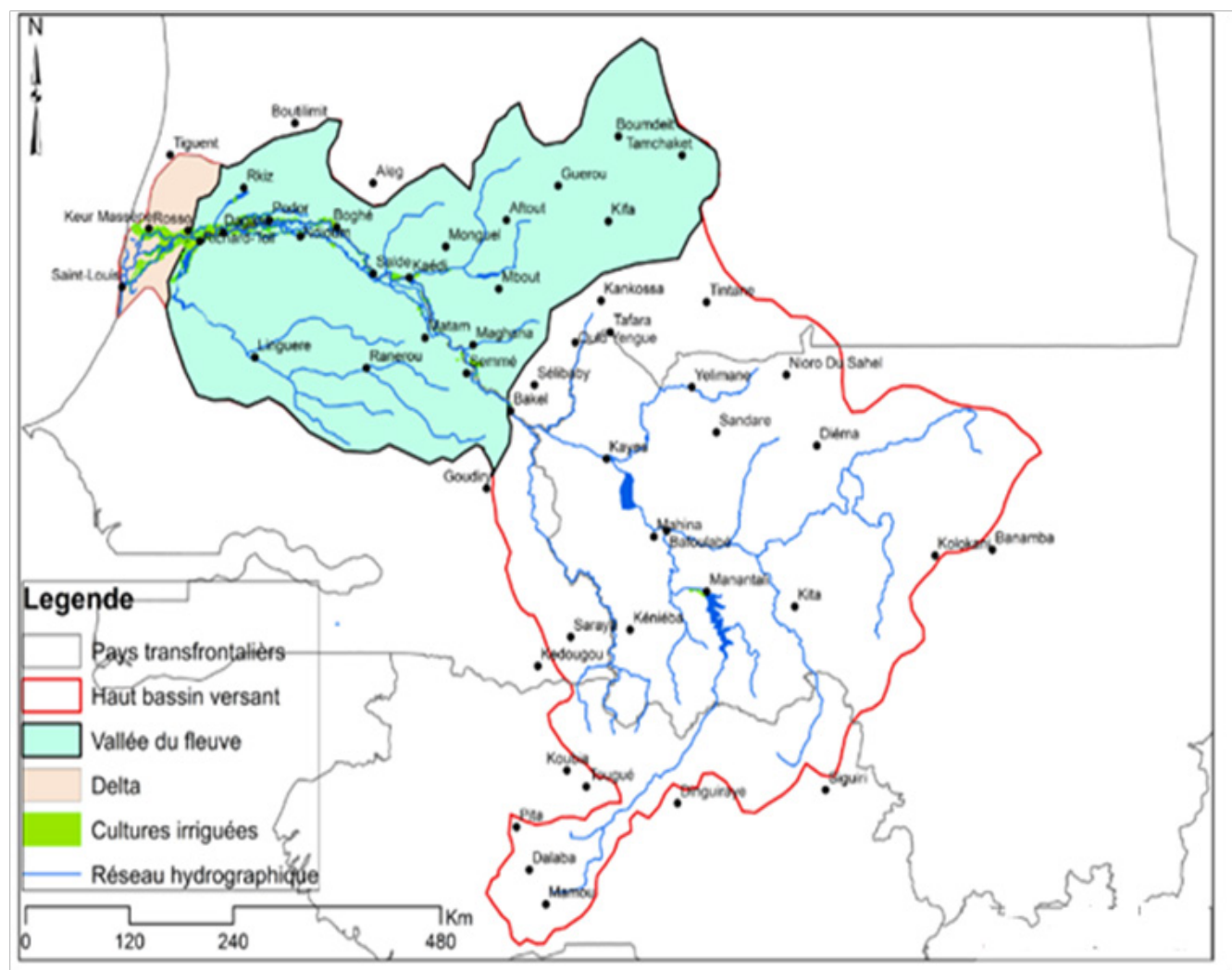

Figure I Presentation Map of the Upper Senegal River Watershed.

\section{Calculation of rainfall and hydrometric indices}

The calculation of rainfall and hydrometric indices makes it possible to identify major trends in time series. At the interannual level, they make it possible to highlight the deficit phases and the surplus phases. They are calculated from the following formula (equ.2):

$$
x_{i}^{\prime}=\frac{x_{i}-\bar{x}}{\sigma(\mathrm{x})}
$$

$x_{i}^{\prime}=$ reduced centred variable for year $\mathrm{i}$ (rainfall index or hydrometric index depending on the variable studied);

$$
\bar{x}=\text { average of the time series over the period 1955-2014; }
$$
2014.

$\sigma(\mathrm{x})=$ Standard deviation of the time series over the period 1955-

The rainfall index is well suited to monitoring changes in vegetation dynamics in relation to changes in rainfall. ${ }^{6}$

\section{Search for trends and breaks in stationarity in time series}

To highlight the stationary or non-stationary nature of the rainfall and hydrometric time series, statistical tests were used for the trend and rupture analysis on average. The term trend refers to the change in the properties of a random process that occurs gradually over the sampling period, while a break is a change that occurs suddenly, with the understanding that the properties remain stable on either side of the year of break. ${ }^{7}$. The Kendall rank correlation test ${ }^{8}$ was used to analyze trends in time series. This test checks the randomness of the time series. The alternative hypothesis of the test is that of a trend. ${ }^{9}$ However, if there is an average break in the series, the test rejects the null hypothesis without the trend hypothesis being valid. The search for breaks in time series was done using Lee and Heghinian Bayesian method, Pettitt test, Buishand and Wood Ellipse test and Hubert segmentation. ${ }^{10}$ The Lee and Heghinian, and Pettitt tests detect a maximum rupture, while the Buishand and Wood Ellipse tests and Hubert's segmentation detect several if they exist in a time series of 
data. They are applied using the KhronoStat 1.01 software developed by the French Institut of Research for Development (IRD).

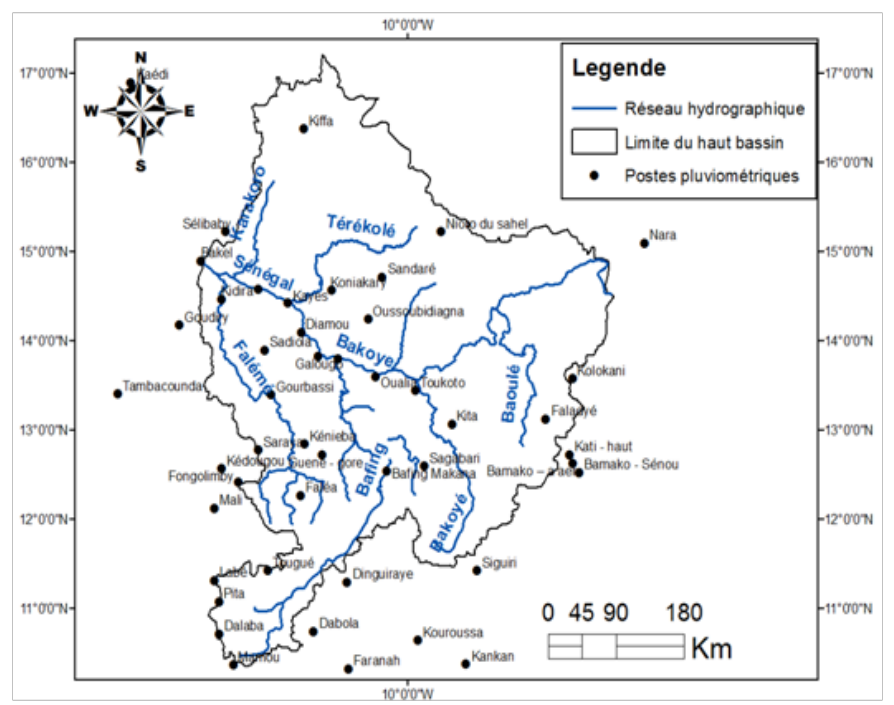

Figure 2 Main tributaries of the upper basin.

Table I Characteristics of the weather stations used

\begin{tabular}{llll}
\hline Stations & Latitude & Longitude & Altitudes (m) \\
\hline Bafing Makana & $12^{\circ} 33$ & $10^{\circ} 15$ & 220,5 \\
Bakel & $14^{\circ} 9$ & $-12^{\circ} 47$ & 25 \\
Kidira & $14^{\circ} 47$ & $-12^{\circ} 22$ & 35 \\
Oualia & $13^{\circ} 36$ & $10^{\circ} 23$ & 108,116 \\
\hline
\end{tabular}

\section{Calculation of average variations around ruptures}

For hydro-rainfall variables whose time series has a break, it is interesting to calculate the average variations on either side of the break by applying the following formula.

$$
D=\frac{\bar{x}_{j}-\bar{x}_{i}}{\bar{x}_{i}}
$$

$D=$ deficit/surplus on both sides of the break

$\bar{x}_{j}=$ average before breakup and

$\bar{x}_{i}=$ after the break-up.

\section{Analysis of land use dynamics}

Land use mapping: The map was done according to a series of operations. The coloured composition made it possible to distinguish the different objects on the images. ${ }^{6}$ It is followed by the choice of training areas (representative sites of the numerical characteristics of the classes) that make it possible to define the spectral signatures of each landscape unit. ${ }^{11}$ These training areas serve as the basis for a supervised classification. Then the "maximum likelihood" classification algorithm was chosen in order to perform the classification. Finally, field surveys validated the classification. ${ }^{11}$ In short, maximum likelihood supervised classification consists in classifying pixels according to their similarity to numerical counts of reference geographical objects previously determined on the image and validated by field surveys. ${ }^{11}$ Based on the thematic classifications obtained, land use maps were produced. Envi 5.1. Software was used for digital processing of satellite images and ArcGIS 10.1 for mapping work.
Assessment of changes in land occupancy units: It was done according to a series of operations. The colored composition made it possible to distinguish the different objects on the images. ${ }^{12}$ It is followed by the choice of training areas (sites representative of the numerical characteristics of the classes) that make it possible to define the spectral signatures of each landscape unit. ${ }^{12}$ These training areas serve as the basis for a supervised classification. Then the "maximum likelihood" classification algorithm was chosen to perform the classification. ${ }^{13}$ Finally, field surveys validated the classification. In short, maximum likelihood supervised classification consists in classifying pixels according to their similarity to numerical counts of reference geographical objects previously determined on the image and validated by field surveys. ${ }^{11}$ Based on the thematic classifications obtained, land use maps were produced. Envi 5.1. Software was used for digital processing of satellite images and ArcGIS 10.1 for mapping work.

\section{Method}

The map was done according to a series of operations. The coloured composition made it possible to distinguish the different objects on the images. ${ }^{6}$ It is followed by the choice of training areas (representative sites of the numerical characteristics of the classes) that make it possible to define the spectral signatures of each landscape unit. ${ }^{11}$ These training areas serve as the basis for a supervised classification. Then the "maximum likelihood" classification algorithm was chosen in order to perform the classification. Finally, field surveys validated the classification. ${ }^{11}$ In short, maximum likelihood supervised classification consists in classifying pixels according to their similarity to numerical counts of reference geographical objects previously determined on the image and validated by field surveys. ${ }^{11}$ Based on the thematic classifications obtained, land use maps were produced. Envi 5.1. Software was used for digital processing of satellite images and ArcGIS 10.1 for mapping work.

Assessment of changes in land occupancy units: It was done according to a series of operations. The colored composition made it possible to distinguish the different objects on the images. ${ }^{12}$ It is followed by the choice of training areas (sites representative of the numerical characteristics of the classes) that make it possible to define the spectral signatures of each landscape unit. ${ }^{12}$ These training areas serve as the basis for a supervised classification. Then the "maximum likelihood" classification algorithm was chosen to perform the classification. ${ }^{13}$ Finally, field surveys validated the classification. In short, maximum likelihood supervised classification consists in classifying pixels according to their similarity to numerical counts of reference geographical objects previously determined on the image and validated by field surveys. ${ }^{11}$ Based on the thematic classifications obtained, land use maps were produced. Envi 5.1. Software was used for digital processing of satellite images and ArcGIS 10.1 for mapping work.

\section{Results}

\section{Rainfall variability}

Over the period 1955-2014, rainfall in the upper basin is marked by very remarkable interannual fluctuations from one station to another. The statistical parameters are recorded in Table 2. There is a succession of surplus and deficit phases (Figure 3). The statistical analysis by the rank correlation test does not show any trend in the annual precipitation history. Figure 4 shows the results of applying the Buishand, and Pettitt tests shows the annual precipitation series on the Figure 5. 
Table 2 Characteristics of rainfall stations

\begin{tabular}{lllllll}
\hline \multicolumn{2}{l}{ Before rupture } & \multicolumn{5}{l}{ After rupture } \\
\hline Stations & Reference & Average & Ecart type & Average & Ecart type & Deficit (\%) \\
\hline Bafing & 1955 & 1289,2 & 90,2 & 1083,8 & 101,6 & 16 \\
Bakel & 1955 & 881,3 & 135,1 & 775,2 & 122,1 & 12 \\
Kidira & 1955 & 681,2 & 47,6 & 572,7 & 53,6 & 15 \\
Oualia & 1955 & 963,7 & 67,4 & 786,9 & 67,6 & 18 \\
\hline
\end{tabular}

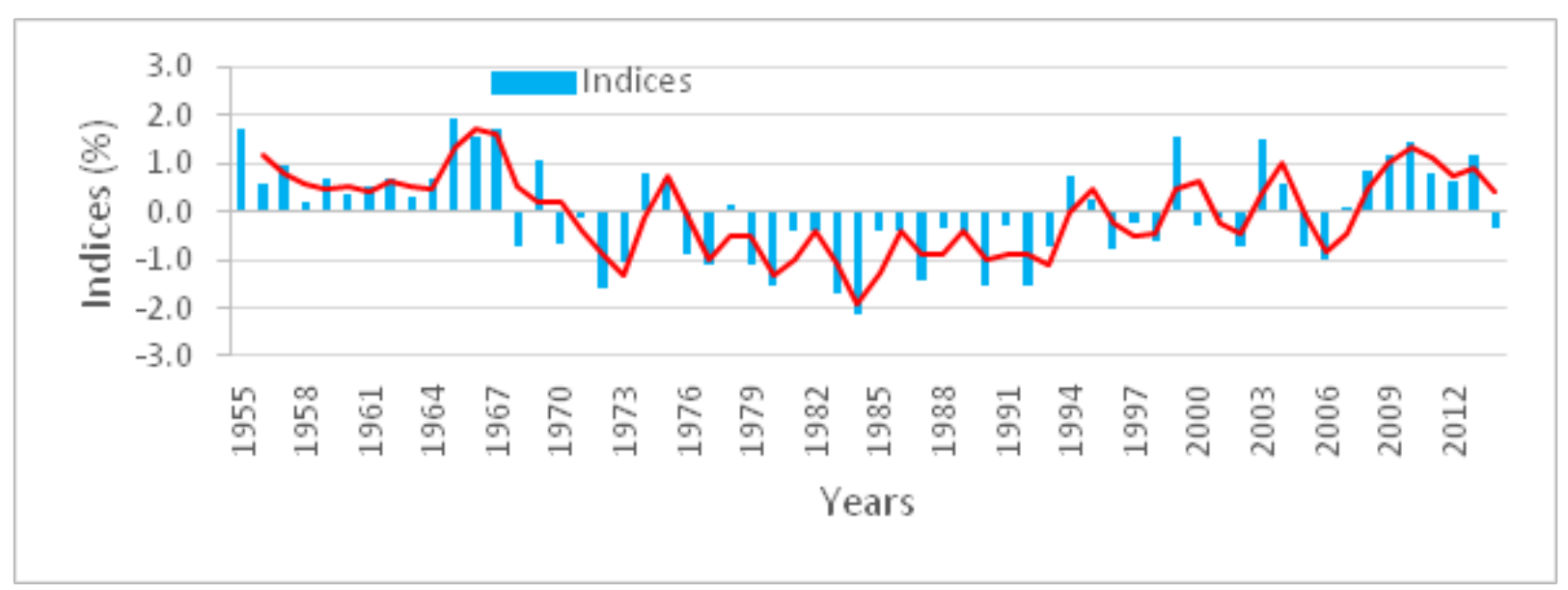

Figure 3 Interannual variability of annual precipitation (I955-20|4).
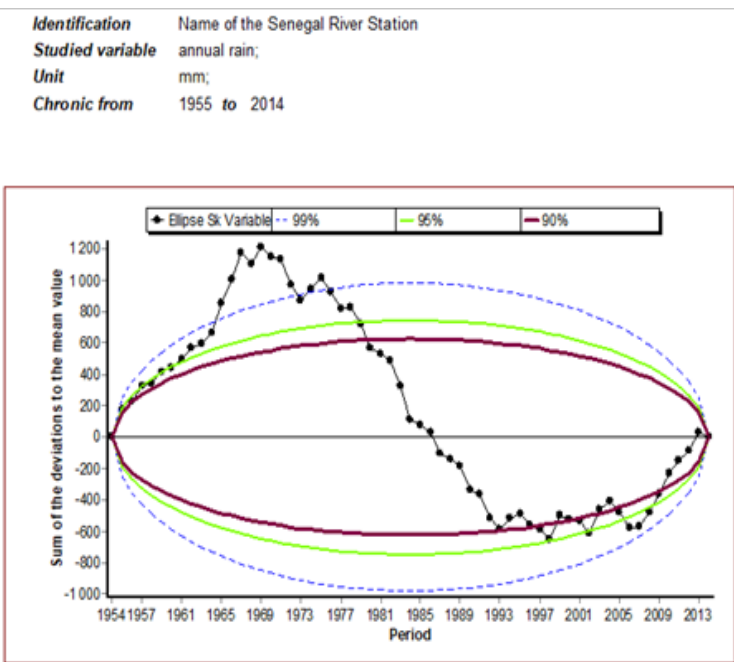

Figure 4 Results of Buishand tests applied to the annual precipitation series.

The average of the pre-rupture and post-rupture sub-series are $879.2 \mathrm{~mm}$ and $717.792 \mathrm{~mm}$ respectively, representing a rainfall deficit of $17 \%$ after the break. The 1955-1969 phase was in surplus. The average rainfall for this phase is $918 \mathrm{~mm}$. During this phase, 1955 and 1965 were very rainy with $983.8 \mathrm{~mm}$ and $962.8 \mathrm{~mm}$ respectively. The 1970-2002 phase was very deficient with an average rainfall of $737.8 \mathrm{~mm}$. The years 1983 and 1984 were particularly dry with respectively 626.6 and $584.4 \mathrm{~mm}$ of rainfall. The 2003-2014 phase was in surplus with an average rainfall of $843.1 \mathrm{~mm}$. The years 2003 and 2010 were particularly rainy with 937.9 and $932.6 \mathrm{~mm}$ of rain recorded respectively.
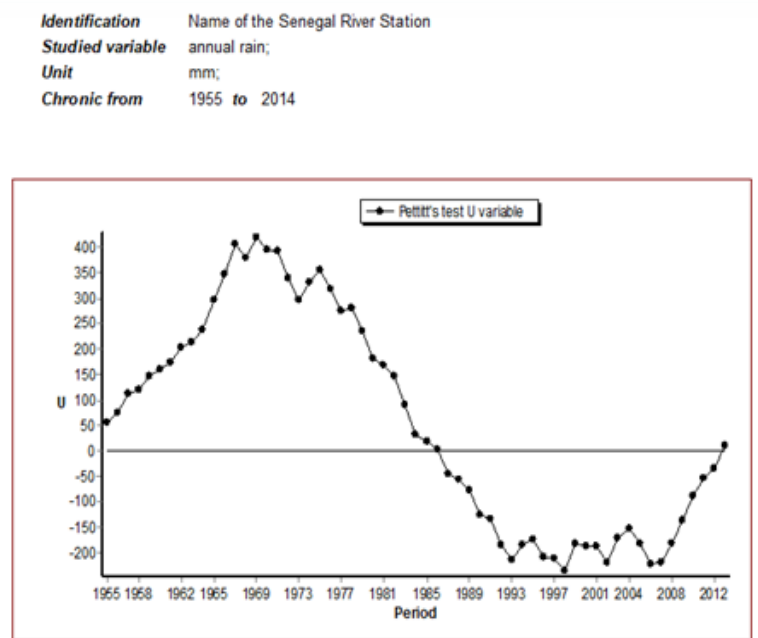

Figure 5 Pettitt test results applied to the annual precipitation series.

\section{Hydrometric variability}

Over the period 1955-2014, interannual variations in flows are quite significant in the upper Senegal River basin at the Bakel outlet. The average of the series is $282.6 \mathrm{~m} 3 / \mathrm{s}$ with a standard deviation of $134 \mathrm{~m}^{3} / \mathrm{s}$. Overall, there are two high-flow phases interspersed with a long low-flow phase (Figure 6).

a. The $1955-1967$ phase is characterized by abundant flows. The average flow rate is $472.5 \mathrm{~m}^{3} / \mathrm{s}$. The years 1955 and 1957 recorded very high modules (570.9 and $579.2 \mathrm{~m}^{3} / \mathrm{s}$ respectively). 
b. The 1968-2011 phase is marked by a decrease in flows. The average flow rate for this phase is $216.8 \mathrm{~m}^{3} / \mathrm{s}$. The years 1983 , 1987 and 1990 were characterized by particularly poor flows (with flows of $140 \mathrm{~m}^{3} / \mathrm{s} ; 110,5 \mathrm{~m} / \mathrm{s}$ and $120.5 \mathrm{~m}^{3} / \mathrm{s}$ respectively). It should be noted, however, that during this long drought phase, the three years 1969, 1974 and 1999 recorded above-average flows.

c. The 2011 to 2014 phase is characterized by excess flows. The average flow rate is $424.1 \mathrm{~m}^{3} / \mathrm{s}$. d. The statistical analysis by the rank correlation test does not show any trend in the annual flow history.

The Buishand test (Figure 7), the Pettitt test (Figure 8), the Hubert segmentation procedure do not reveal any breaks in the annual flow history. Only the Lee and Heghinian test shows a rupture in the annual flow chronicle in 1969. The mean values of the pre-break and post-break sub-series are $472.5 \mathrm{~m}^{3} / \mathrm{s}$ and $157.4 \mathrm{~m}^{3} / \mathrm{s}$ respectively, representing a hydrometric deficit of $66 \%$ after the rupture.

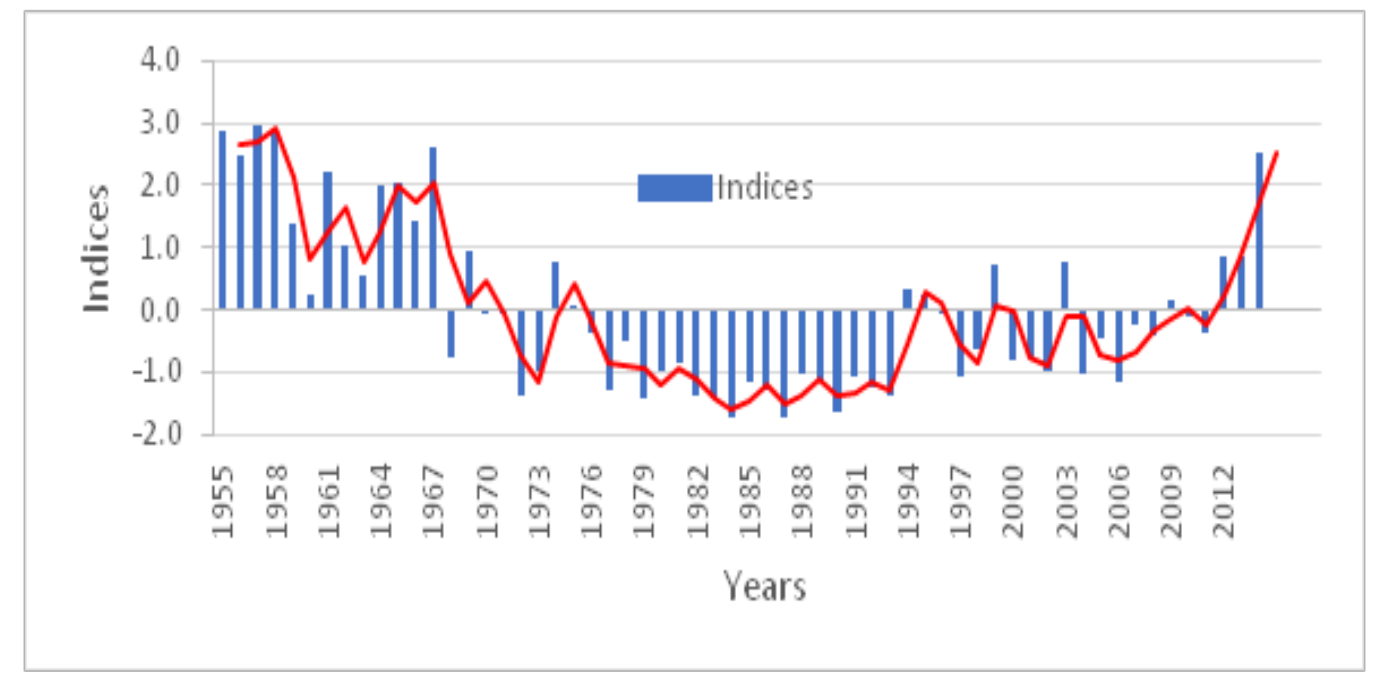

Figure 6 Interannual variability of annual flows (1955-2014).

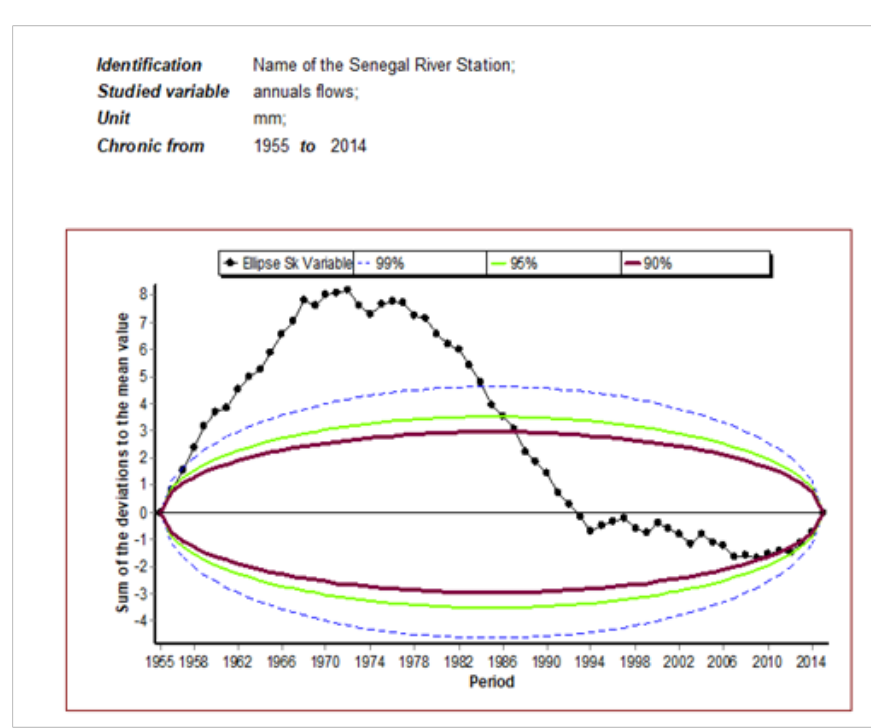

Figure 7 Buishand test results applied to the annual flow series.

\section{Land tenure dynamics}

The statistical analysis of the information made possible the accurate characterization of the types and extent of land use changes.

Land use in 2007 and 2014: From the analysis of the 2007 land use map (Figure 9) and Table 4, we note the following trends: predominance of forest and savannah, which represent $48 \%$ of the total area of the study area, wetlands with $23 \%$ and bare soils, which

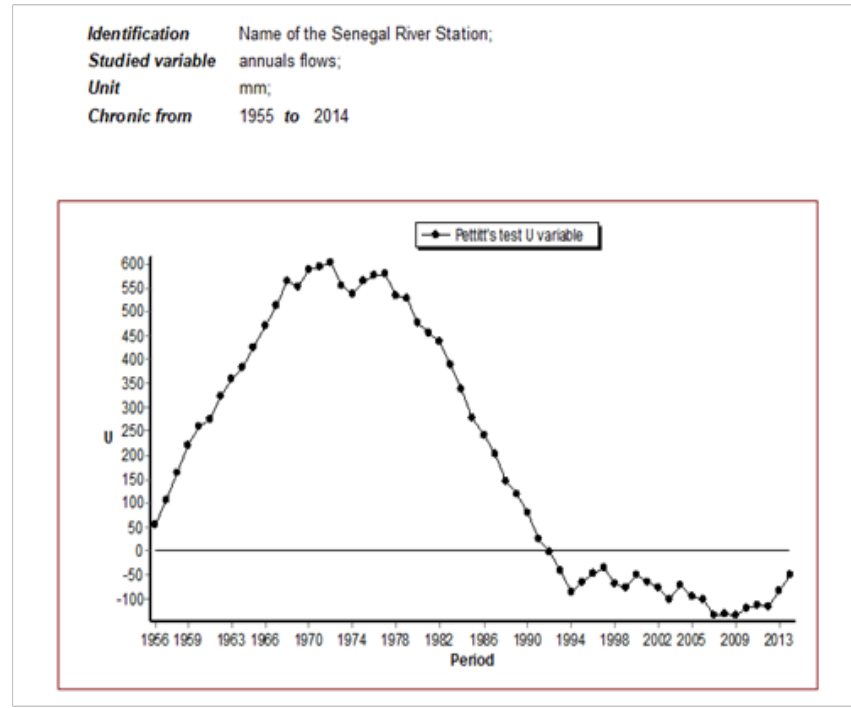

Figure 8 Pettitt test results applied to the annual flow series.

cover $13 \%$ of the area. Crop and fallow formations occupy $10 \%$ of the surface area and $6 \%$ of the water bodies. For the year 2014 (Figure 9), crops and fallows increased significantly to $17.8 \%$, bare soils occupy $21.8 \%$ and $16.95 \%$ of the total area is occupied by wet soils, $5.8 \%$ by water bodies, and $37.65 \%$ by forests and savannas (Table 3 ).

The impact of the drought is evident on the Manantali dam. According to the Modis image portions, there is a significant decrease 
in the extent of the water body in favour of bare soils, estimated at about $21.8 \%$. These results indicate the effects of climate change on water bodies (Figure 10).

\section{Land cover confusion matrix for 2007 and 2014:}

The analysis of the different confusion matrices showed the overall accuracy obtained in this study. Land use classes such as forest cover declined by $10.4 \%$ (2007-2014). The 2007 land use scenario produces the highest flows. The functioning of the hydrosystem is subject to seasonal climate variability. In the upstream sector of the basin, the constancy of vegetation (density, leaf index) and soil condition variables (water retention, hydraulic conductivity) have very little influence on the variability of the hydrosystem's response to rainfall events. The area of dense rainforest that occupied $48 \%$ of the basin in 2007 was reduced to $37.6 \%$ in 2014 . This forest regression in favor of the "forest-crop" and "crop-forest-crop" mosaics has considerably affected the hydrological responses of the upper basin hydrosystem. In 2007 , where there is $48 \%$ dense forest cover, flows remain the lowest, while in 2014, where dense forest cover is reduced to $37.6 \%$, flows are very high, especially during the dry season (Figure 11).

Table 3 Types of land use

\begin{tabular}{lllllll}
\hline \multirow{2}{*}{ Land use categories } & \multicolumn{2}{l}{ Area $\mathbf{2 0 0 7}$} & \multicolumn{2}{l}{ Area $\mathbf{2 0 1 4}$} & \multicolumn{2}{l}{ Differences about } \\
\cline { 2 - 7 } & $\mathbf{( \% )}$ & $\mathbf{( \mathbf { k m } ^ { 2 } )}$ & $\mathbf{( \% )}$ & $\mathbf{( \mathbf { k m } ^ { 2 } )}$ & Categories & Total area \\
\hline bare floors & 13 & 28340 & 21,8 & 47524 & 67,7 & 8,8 \\
wet soils & 23 & 50140 & 16,95 & 36951 & $-26,3$ & $-6,05$ \\
Forests and savannahs & 48 & 104640 & 37,65 & 82077 & $-21,6$ & $-10,35$ \\
Crops and fallows & 10 & 21800 & 17,8 & 38804 & 78,0 & 7,8 \\
Water bodies & 6 & 13080 & 5,8 & 12644 & $-3,3$ & $-0,2$ \\
Total & 100 & 218000 & 100 & 218000 & & \\
\hline
\end{tabular}
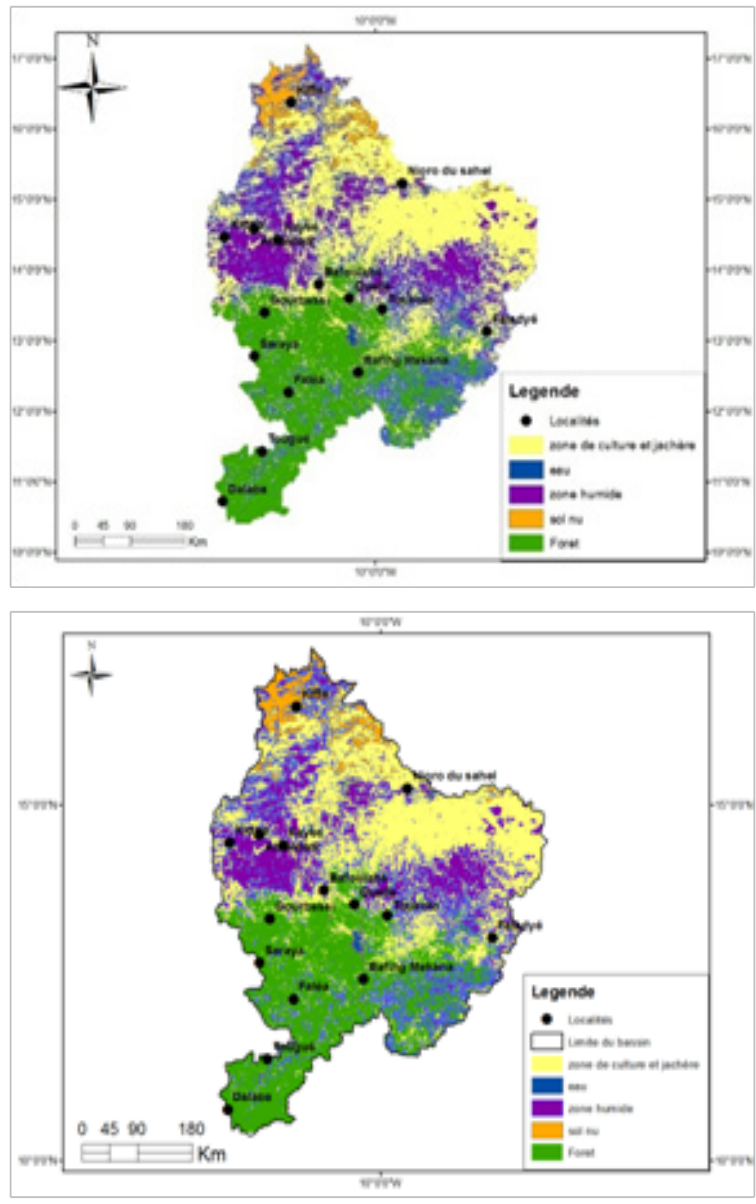

Figure 9 Land use map of 2007 and 2014.

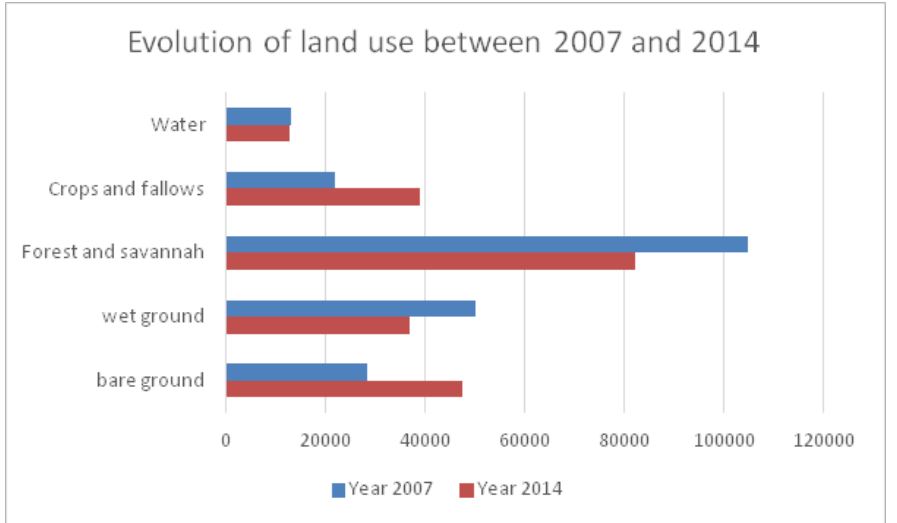

Figure 10 Evolution of land use types from 2007 to 2014.

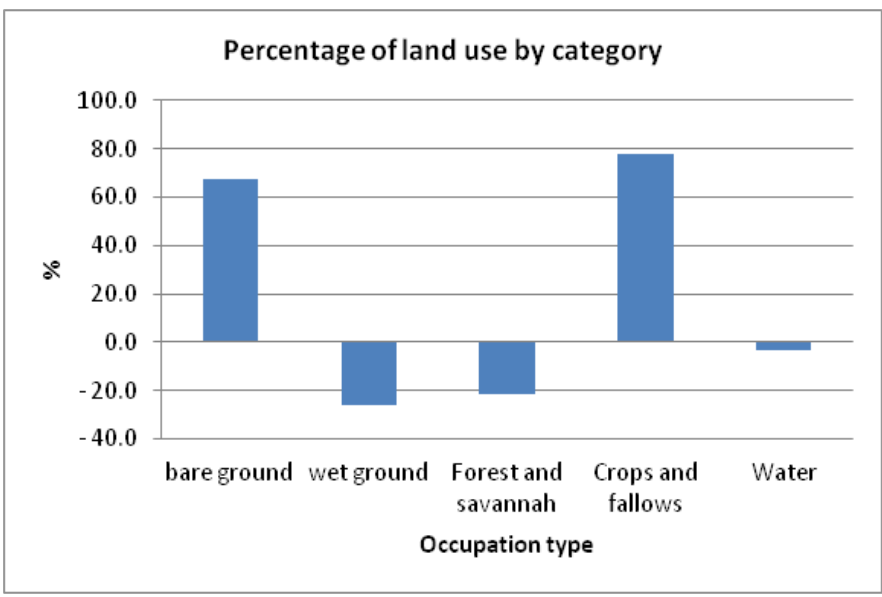

Figure II Evolution of land use types. 


\section{Discussion on the rainfall recession and its impacts on water resources}

Climate change in the West African hydrosystem, and particularly in the Senegal River basin and Gambia, has been marked by a rainfall disruption since the 1970s. In addition, the climate crisis has not affected the entire hydrosystem in the same way. Its amplitude is not uniform. Some unique characteristics are related to the influence of the Fouta Djalon microclimate (foehn effect) which combines with regional and global climate factors to control the temporal variability of rainfall in the Fouta Djalon area. These results are consistent with those obtained by. ${ }^{14}$ The work of ${ }^{3}$ has highlighted significant correlations between some regional interannual rainfall trends in West Africa and thermal anomalies in the tropical Atlantic Ocean. The resulting interannual rainfall deficit is estimated at $-10 \%$. In West Africa, these rainfall deficits are in the order of $-20 \%$, but can sometimes exceed $-25 \%{ }^{15,16}$ Low water was particularly affected by this drought event. According to ${ }^{1}$ the low water levels of the Sudano-Sahelian rivers are the lowest of the chronicles observed. Between 1970 and 1990, there is a high concentration of years with lower monthly low-flow monthly values. In short, since the 1970s, all the variables characteristic of water regimes have been declining, resulting in the advent of drought with its dramatic consequences on land use indicators. ${ }^{17-29}$

Analyses of land use dynamics in the upper Senegal River catchment area from 2007 to 2014 showed an increase in arable land and planted or bare land. The data collected and analysed showed a trend and increase in agricultural areas (from $10 \%$ to $17.8 \%$, urban areas (habitats) and bare soil: from $13 \%$ to $21.8 \%$ at the expense of other categories of land use units. Areas of dense vegetation (forests) have declined significantly (from $48 \%$ to $37.65 \%$ ) and water bodies from $6 \%$ to $5.8 \%$. These modifications are explained by anthropogenic actions (construction of the Manantali and Felou dam, massive deforestation, degradation of the Baoulé and Bafing wildlife reserves, high water retention for agriculture, etc). on natural resources in general and plant formations in particular. In short, the drought or climate crisis highlighted in this study has influenced the hydrological regime of rivers and affected land use patterns in the Senegal River and Gambia basins.

\section{Conclusion}

The upper Senegal River basin experienced a wet period before 1970 with alternating wet periods, normal and dry years. Like other hydrosystems in West and Central Africa, the Senegal River basin is affected by a period of rainfall recession that began in 1969. This drought is highlighted by a significant break in the stationarity of the rainfall observation series. Over the entire study area, rainfall patterns have undergone significant changes (westward shift of high rainfall isohyets) resulting in a general decrease in annual rainfall, an increase in annual average temperatures and sunshine, and a decrease in the duration of the rainy season. Drought sequences and their impacts on hydrological regimes and underground reservoir emptying conditions cause water supply difficulties for the populations of some countries in the basin such as Senegal and Mauritania. In order to ptimize the sustainable development of hydrosystems, therefore they must be managed by taking into account their sensitivity to constantly changing climatic variability and changes in vegetation cover.

\section{Acknowledgments}

None.

\section{Conflicts of interest}

The authors declares that there is no conflict of interest.

\section{References}

1. Bodian A. Characterization of the recent temporal variability of annual rainfall in Senegal (West Africa). Physio-Geo. 2014;8:297-312.

2. Descroix L, Diongue-Niang A, Dacosta $\mathrm{H}$, et al. Evolution of extreme rainfall and recrudescence of floods in the Sahel. Climatology. 2013;10:37-49.

3. Descroix L, Mahe G, Olivry JC, et al. Anthropogenic and environmental factors of the upsurge of floods in the Sahel. In: Sultan B, et al, Editors. Rural societies in the face of climate and environmental change in West Africa. 2015;153-170.

4. Diallo H, Bamba I, Barima YSS, et al. Combined effects of climate and anthropogenic pressures on the evolutionary dynamics of vegetation in a protected area of Mali (Fina Reserve, Boucle du Baoulé). Drought. 2011;22:97-107.

5. Krysanova, White. Advances in water resources assessment with SWATan overview. Hydrological Sciences Journal. 2015;60(5):771-783.

6. Lubes-Niel H, Masson JM, Paturel JE, et al. Climate variability and statistics. Study by simulation of the power and the robustness of some tests used to check the homogeneity of chronicles. Journal of Water Sciences. 1998;3:383-408.

7. Mahe G, Olivry JC. Climate variability and statistics. Simulation study of precipitation and flow variations in West and Central Africa from 1951 to 1989. Drought the power and robustness of some tests used to verify the homogeneity of chronic. Journal of Water Sciences. 1995;6(1):109-117.

8. Nicholson SE. On the question of the "recovery" of the rains in the West African Sahel. Journal of Arid Environments. 2005;63(3):615-641.

9. Mehan, Narayanan K, Neupane. Climate Change Impacts on the Hydrological Processes of a Small Agricultural Watershed. Climate. 2016;4(56):1-22

10. Druyan LM, Fulakeza M, Lonergan P. The impact of vertical resolution on regional model simulation of the West African summer monsoon. International Journal of Climatology. 2008;28:1293-1314.

11. Perreault L. Bayesian retrospective analysis of a break in sequences of hydrological random variables. Thesis cotutelle ENGREF/GRESE and Univ. Quebec/INRS-Eau. 2000. p. 200

12. Kouassi AM, Kouame KF, Ahoussi KE, et al. Combined impacts of climate change and anthropogenic pressures on changes in vegetation cover in the N'zi-bandama watershed (Côte d'Ivoire). Rev Isee Sci Technol. 2012;20:124-146.

13. Konaré A, Zakey AS, Solmon F, et al. A regional climate modeling study of the effect of desert dust on the West African monsoon. Journal of Geophysical Research. 2008;113:D12206.

14. Paturel JE, Servat E, Delattre MO. Analysis of long-term rainfall series in West and Central Africa, non-Sahelian climate variability. $J \mathrm{Sci}$ Hydrol.1998;43(3):937-945.

15. Goula BTA, Savane I, Konan B, et al. Impact of climate variability on the water resources of the N'zo and N'zi basins in Côte d'Ivoire (tropical humid Africa). Vertigo. 2014;7(1):1-12,

16. Le Barbé L, Lebel T, Tapsoba D. Rainfall variability in West Africa during the years 1950-90. J Climatol. 2002;15(2):187-202.

17. Lubes NH, Masson JM, Paturel JE, et al. Climatic and statistical variability. Study by simulation of the power and the robustness of some tests used to check the homogeneity of chronicles. Journal of Water Sciences. 1998;3:383-408 
18. Servat E, Paturel JE, Lubes-Niel H, et al. Reduced runoff in West and Central Africa. Earth sciences and planets. 1997;325:679-682.

19. Brou YT. Climate, socio-economic changes and landscapes in Côte d'Ivoire. Mém HDR Univ Sci Techn Lille France. 2005. p. 212.

20. Ardoin BS. Hydro-climatic variability and impacts on water resources of major watersheds in the Sudano-Sahelian zone. Thèse Univ. Montpellier II, France. 2004. 330 p.

21. Ouedraogo M. Contribution to the study of the impact of climate variability on water resources in West Africa. Analysis of the consequences of persistent drought: hydrological standards and regional modeling. Univ Montpellier II. Th Doctorate. 2001;1-257.

22. Diello P. Climate - Human - Environment Interrelations in the Burkinabe Sahel: impacts on surface states and hydrological modeling. PhD Thesis, University Montpellier II, Sciences and Techniques of Languedoc. 2007. $368 \mathrm{p}$.

23. Ali A, Lebel T. The Sahelian standardized rainfall index revisited. Int J Climatol. 2009;29:1705-1714.

24. Niang, Kane. Morphological and Hydrodynamic Changes in the Lower Estuary of the Senegal River: Effects on the Environment of the Breach of the 'Langue de Barbarie' Sand Spit in 2003. In: Diop S, et al. Editors. The Land/Ocean Interactions in the Coastal Zone of West and Central Africa, Estuaries of the World (DOI: 10.1007/978-3-319-06388-1_3). Springer International Publishing. 2014;23-39.
25. Afiesimama AE, Pal JS, Abiodun BJ, et al. Simulation of West African monsoon using the RegCM3. Part I: Model validation and interannual variability. Theoretical and Applied Climatology. 2006;86(1-4):23-37.

26. Browne NAK, Sylla MB. Regional climate model sensitivity to domain size for the simulation of the West African monsoon rainfall. International Journal of Geophysics. 2012(2012):ID 62583117.

27. Cook KH, Vizy EK. Coupled Model Simulations of the West African Monsoon System: Twentieth- and Twenty-First-Century Simulations. AMS. 2006.

28. Gbobaniyi EO, Sarr A, Sylla MB, et al. Climatology, annual cycle and interannual variability of precipitation and temperature in CORDEX simulations over West Africa. International Journal of Climatology. 2014;34:2241-2257.

29. Diallo I, Bain CL, Gaye AT, et al. Simulation of the West African monsoon onset using the HadGEM3-RA regional climate model. Climate Dynamics. 2014;45:575-594. 